\title{
Case Report: Exploring the Contributory Role of Autism Spectrum Disorder Symptomology to the Viewing of Indecent Images of Children (IIOC) and the Experience of the Criminal Justice System
}

\begin{abstract}
Purpose: Allely and Dubin (2018) and Allely, Kennedy and Warren (2019) have emphasised that there are a range of innate vulnerabilities in many individuals with autism spectrum disorder (ASD) who are charged with the viewing of Indecent Images of Children (IIOC). Currently, the understanding between the association between ASD and the viewing of IIOC is poorly recognised and understood both by the general public as well as clinical and legal professionals. Design: A detailed case study exploring the contributory role of ASD symptomology to the viewing of IIOC. In this case study the experience of the criminal justice system is also explored. Finding: It is hoped that this case study will provide insight and understanding into the association and raise awareness of the need to consider this at all stages of the criminal justice system, including in sentencing decisions. It will also more effectively inform the development of appropriate preventative strategies and timely interventions. Originality: This is the first detailed case study which explores the contributory role of ASD symptomology to the viewing of IIOC in the academic peer reviewed literature.
\end{abstract}

Keywords: Autism Spectrum Disorder; sex offending; child pornography; indecent child images; onlineoffending; prison; courts; police; sentencing; Indecent Images of Children; IIOC. 


\section{Introduction}

\section{Autism Spectrum Disorder}

Autism spectrum disorder (ASD) is an early onset, pervasive, and lifelong neurodevelopmental disorder which is characterized by impairments in social communication and repetitive, restricted behavior patterns and atypical response to sensory stimuli (DSM-V, American Psychiatric Association, APA, 2013). Across individuals with ASD, there is also significant variability in both intellectual and communicative ability (McPartland, Law, \& Dawson, 2016). The "true" prevalence of ASD is currently unknown (Fernell, Eriksson, \& Gillberg, 2012). Lyall and colleagues (2017) highlighted that, to date, there has only been one rigorous study of ASD prevalence in adults (Brugha et al., 2011). This investigation, which was conducted in England in 2007, produced an estimate of ASD in 1\% in the general population which is consistent with the findings from earlier investigations (e.g., Simonoff, 2012). In the general population, the male-female ratio for ASD prevalence is between 4 and 5:1 (Fombonne, 2009). The fifth edition of The Diagnostic Statistical Manual (DSM-V, American Psychiatric Association, APA, 2013) characterises, what was previously three core areas of impairment, two core areas of impairment in ASD: (1) "persistent deficits in social communication and social interaction" and (2) "restricted, repetitive patterns of behavior, interests, or activities" (APA, 2013). Across individuals, impairment to these two core areas differs with respect to symptoms and severity of symptoms.

\section{ASD and sexual offending}

It is important to emphasise in any discussion of ASD and offending that individuals with ASD are not more likely to carry out offending behaviours compared to the general population (e.g., Mouridsen et al., 2008). However, research has indicated some of the ASD symptomology which can contribute to a variety of offending behaviour (e.g., Baron-Cohen, 1988; Everall \& Lecouteur, 1990; Chesterman \& Rutter, 1993; Siponmaa et al., 2001; Barry-Walsh \& Mullen, 2004; Schwartz-Watts, 2005; Mouridsen et al., 2008; Ledingham \& Mills, 2015; Allely \& Creaby-Attwood, 2016; Lazaratou, Giannopoulou, Anomitri, \& Douzenis, 2016; Melvin, Langdon, \& Murphy, 2017; Allely \& Faccini, 2018; Allely, 2019). For example, there is a growing number of studies which have explored the core features of ASD which may contribute to inappropriate sexual behaviours. Mogavero (2016) found a number of studies which indicate a significant proportion of deviant or sexual offending is frequently driven by symptoms inherent to ASD rather than being due to any malice. Allely and Creaby-Attwood (2016) identified a small number of studies which had discussed some of the key features of ASD that can contribute to sexual offending behaviour. Some of these 
include an "obsession or preoccupation with certain things (e.g., women's underwear), failure to conform to social conventions, impaired Theory-of-Mind (ToM), impaired ability to decode language and social gestures and a limited repertoire of appropriate behaviour" (Allely \& Creaby-Attwood, 2016, pp. 47). ToM refers to the ability to explain and predict the behaviour of other people by discerning mental states including intentions, beliefs, desires, or emotions (Baron-Cohen, Leslie, \& Frith, 1985; Gallagher \& Frith, 2003; Kana et al., 2015). The other core features of ASD which have also been found to have a potential contribution to sexual offending (as well as in other types of offending behaviours) include an impaired ability to appropriately interpret the victim's negative facial reactions (e.g., expressions of fear and distress) in response to their sexual advances (Freckelton \& List, 2009).

Numerous published case studies have highlighted the importance of recognising and understanding the potential innate vulnerabilities in many individuals with ASD which may increase their risk or vulnerability of engaging in a sexual offence (such as, an impaired ToM and also repetitive and stereotyped behavioural patterns and persistent preoccupation (e.g., Murrie et al., 2002). Murrie and colleagues (2002) describe case studies involving individuals with ASD who had engaged in different types of sexual offending behaviours. They outline the various features or symptomology of ASD which may have contributed to the sexual offending in the cases they described in their paper. Some of these features include: "Interpersonal naiveté", sexual frustration, immediate confession (which may be associated with impaired deception and ToM) and sexual preoccupation. It is important to note that immediate confession is linked to conviction/getting caught but not in displaying the behaviour itself, namely, the viewing of IIOC. Haskins and Silva (2006) have argued that it may appear that considering the offending behaviour carried out by individuals with ASD is related to an impaired ToM or abnormal repetitive and restricted interests is simpler and an easier explanation. However, their offending may frequently comprise of impairments in both of these domains.

Potential Innate vulnerabilities in some individuals with ASD charged with the viewing of Indecent Images of Children (IIOC)

Allely and Dubin (2018) and Allely, Kennedy and Warren (2019) have emphasised that there are a range of potential innate vulnerabilities in many individuals with ASD who are charged with the viewing of IIOC. Individuals may explore the internet for sexual education or to satisfy their sexual needs as a result of the lack of sexual outlets with peers/friends (e.g., Attwood et al., 2014). It is important to clarify here that accessing IIOC is a maladaptive strategy that may be developed by individuals with ASD, with a lack of knowledge regarding criminality of the behavior. Many individuals with ASD have average or above average intelligence while their social maturity, on the other hand, is that of someone much younger. This can result in them being more interested and comfortable in befriending individuals who are younger than themselves but who are at the same level as them both socially and emotionally (Cutler, 2013). With regards to the viewing of IIOC, individuals with ASD may also be completely unaware that what they have done is a criminal offense. 
The lack of awareness that they have even committed a crime may be due to their inability to recognise the facial expressions in the images of the children. This impaired ability to recognise facial expressions (such as fear) is well-supported by the findings from a substantial body of literature which includes empirical studies (e.g., Woodbury-Smith et al., 2005; Uljarevic \& Hamilton, 2013). Additionally, many individuals with ASD may inadvertently view IIOC due to their inability or difficulty in being able to correctly guess the age of the individuals in the images and sometimes the boundaries/distinction between an adult and a child is blurry. Given that the legality and severity of the offense is determined by the age of the victims in the images which are viewed by the defendant this is an important factor to understand and consider (Mahoney, 2009).

Exploring sexuality on the internet through the viewing of IIOC is one way for some individuals with ASD to try to develop an understanding of relationships and sexuality rather than being a precursor to sexual offending towards a minor. For individuals with ASD, the desire for this material can end up being particularly excessive and compulsive as with many things that are of interest to them (Mesibov \& Sreckovic, 2017). It has been argued that, for individuals with ASD, the internet coupled with sexuality can result in a "lethal combination" (Mahoney, 2009). There are numerous cases (based on anecdotal evidence) where the individual with ASD has been found with a substantial collection of pornographic material (e.g., involving children) with thousands of files which are not even opened. In cases such as this, it is clear that the collecting of the pornographic material forms part of the ritualistic nature of ASD. The obsessive collecting and categorisation of the material (such as IIOC) can be appealing to an individual with ASD and not necessarily evidence that they are more likely to act on their sexual interests and commit a sexual offence against a minor. Unfortunately, current risk assessment for such individuals does not consider this ritualistic component of ASD in individuals with ASD who are charged with the viewing of IIOC. Instead, the more images you have the more 'risky' (higher the level of risk) you are considered to be. There is no research which supports this, however, in individuals without ASD let alone in individuals with ASD (Stabenow, 2011, Mahoney, 2009).

Individuals with ASD, may be completely unaware of the broader issues like where and how they got those files or images, who else might be able to access them and what the consequences (and impact on) are for the minors in the images (recognising that they are victims and not willing participants). Another issue is that individuals with ASD have a very literal view of the world and, as a result, they would not consider that something that is illegal could be so freely available on the internet. They would not even think to question this (Mesibov \& Sreckovic, 2017). The media is also saturated with marketing materials consisting of risky images of teenage models or images where they have made the older models appear to look "barely legal". Images like these can be confusing for individuals with ASD which makes it even more difficult for them to determine what pornography is illegal and what is not (Mesibov \& Sreckovic, 2017). Lastly, there has been no research which has found any evidence to support the notion that extreme sexual content is predictive of dangerousness (Osborn, Elliott, Middleton, \& Beech, 2010). However, viewing extreme sexual material is not always indicative or a reflection of deviant sexuality. Instead, it can be what is referred to as "counterfeit 
deviance" (e.g., naïve curiosity) in offenders with ASD (Hingsburger, Griffiths, \& Quinsey, 1991; Mahoney, 2009).

Present study

This is the first case study which explores the contributory role of ASD symptomology to the viewing of IIOC. It also explores the experience of the criminal justice system.

\section{Method}

Participant

The present study is based on a case study of P.J. who was charged and found guilty of downloading indecent child images ("CIVIC GOVERNMENT (SCOTLAND) ACT 1982. SECTION 52(1)(A) - CHILD SEXUAL”). P.J. did not produce or share any content. P.J.'s offence was a strictly non-contact offence. However, within the law, no distinction is made between contact and non-contact offenses of this type. P.J. was 30 years of age when he was charged and 31 years of age when he was convicted. P.J. was sentenced to prison for 13 months (a total of 6.5 months in prison given good behaviour). He was formally diagnosed with ASD when he was 31 years of age, a week after being released from prison on bail, pending an appeal hearing. Despite receiving this diagnosis later in adulthood, P.J. had a long history of being viewed by others as being "different" and this caused him concerns at various stages throughout his childhood and teenage years but no health professional suggested further investigation was necessary. He reports that he found it difficult to make friends and was bullied, physically and psychologically throughout his time at school.

\section{Procedure}

A 34-item questionnaire was developed by the author to explore the experiences that this participant had throughout his criminal justice experience and since he has been released from prison. Some examples of the questions include: "7. What was your experience of your interactions with police? For instance, were there any challenges or difficulties? Was there anything you found particularly stressful? Please give as much detail as possible."; " 8 . What was your experience of the court proceedings? For instance, were there any challenges or difficulties? Was there anything you found particularly stressful? Please give as much detail as possible.”; “13. Did you encounter any difficulties or challenges while in prison?"; "15. Do you think your diagnosis of autism impacted on your experiences in prison? If so, in what ways? Please give as much detail as possible. Examples would be helpful.”. Questions 20 to 26 were adapted from an already published and well-regarded questionnaire - the MEASURING THE QUALITY OF PRISON LIFE PRISONER QUESTIONNAIRE (MQPL, Liebling, Hulley, \& Crewe, 2011). The questions 20 to 26 asked about whether the participant had 
ever spent time in a care and separation unit; received an adjudication (a 'nicking') while in prison; experienced the use of minimising and managing physical restraint procedures by officers in the prison; had ever been on an ACCT (Assessment, Care in Custody and Teamwork plan) or F2052SH (self-harm monitoring form); had ever self-harmed or attempted suicide and whether the participant had ever done an accredited Offending Behaviour course (for example Thinking Skills Programme, Anger Management, or others). P.J. completed this questionnaire approximately a year and a half following his release from prison (Scottish Prison). Ethical approval was granted by the School of Health \& Society Research Ethics Panel at the University of Salford, United Kingdom (ethics code: HSR1819-096).

\section{Findings and Discussion}

In this section the following areas are explored in detail, namely, P.J.'s experience of receiving a diagnosis of ASD; his experiences with police; his experiences during the court proceedings; his experiences in prison; his experiences when released from prison and also his suggestions and ideas for what support or interventions would have been useful at all stages of his involvement with the criminal justice system.

\section{Formal Diagnosis of ASD}

In preparation for sentencing, P.J.'s therapist prepared a report on his behalf where there was reference made to the possibility of ASD. However, this was not followed up. Prior to sentencing, P.J. was sent to a criminal justice social worker who provided a court ordered report. This report did not make any reference to possible ASD and contained negative references to P.J. For instance, it stated that he "had no empathy". This is despite the fact that P.J. admitted his guilt and the harm he had caused. This is a particularly detrimental thing to include in a court ordered report. It is highly possible in this case that the social worker interpreted the clinical presentation of ASD (at this point undiagnosed) to be suggestive of a lack of empathy. It is a common misconception that individuals with ASD do not have empathy. Individuals can appear to lack empathy and lack emotional expression but this does not necessarily reflect what they are feeling and thinking inside.

The diagnosis of ASD was also helpful and important for P.J. because “...the diagnosis gave crucial context and understanding to my family and friends; these obsessive, sometimes unconscious patterns of behaviour and the link between ASD and this manner of offending detailed in academic literature, helped them understand how I could have committed such an offence". His diagnosis of ASD also helped P.J. to understand some of his behaviours surrounding the collection of IIOC, for instance: “.....my tendency to collect an entire related series' of content irrespective of whether it interested me or not...”. 
It is also crucial to point out here the age at which P.J. was first exposed to IIOC. He was introduced to the material when he was 12 years of age by a friend (who was 11 years old) at school. It was clear to P.J. he had been sharing this material for some time. He states: “...my offending was based on habits created when I was exposed to such material at the age of 12, when I was of similar age to those in the images I accessed and the actual searching for and downloading of the images was what gave me comfort rather than the content". Taken within the psychological context of someone with ASD, the images will have become fixated at this stage and this type of material, as P.J. himself says "gave him comfort". This became his preoccupation or obsessive interest in the same way that an individual exposed to trains at that age, might develop a fixation or preoccupation with trains. Ceasing or interrupting the pursuit of these interests can cause individuals with ASD significant distress and anxiety.

Experiences with police when arrested and questioned

P.J. first came into contact with police around $7 \mathrm{am}$ on the day he was arrested. The police searched his house and seized every device that could connect to the internet and store data. He was taken to the local police station and waited in an interview room while they performed an initial analysis of the devices to determine if charges were going to be made. They found evidence of indecent material on one of the devices and he was transported to another station for questioning. At the station he was put in a cell for most of the day, before being interviewed in the evening. He only had the briefest of moments with which to speak with his solicitor who advised him to simply answer "no comment" to every question for the time being. Initially, P.J. describes the officers interviewing him as appearing friendly and approachable. This changed when they realised that he was not going to answer their questions. It was at this point that P.J. reported that they began asking him questions in a way which was hostile (e.g., "Do you think it's right for bad things to happen to children"). After the interview, they told P.J. that he could ask the guards if he needed to talk about anything, knowing the stress that he must be under. P.J. was kept overnight and then transported to court in the morning where he was then kept in a cell for an additional six or more hours. Eventually, he was able to speak with his lawyer, was charged and released on bail.

P.J. found his experience of first contact with the police to be stressful and finds it difficult to discuss his interactions with the police given the level of stress and intimidation he felt at the time. One of the things that made this experience particularly stressful was his difficulty in recalling the events he was being asked about in temporal order or sequence. Specifically, he states: "The process of recalling the events in any order is distressing to the point that I had to take frequent pauses when answering this particular question due to fears that I would suffer a panic attack (this has happened a number of times in the past, when explaining the events to my family, my therapist and - much later - the Criminal Justice Social Work team)". The point here that P.J. makes regarding being able to recall events in any order is an important one. Recent research has 
shown that individuals with ASD are often impaired in their ability to recall events in a sequential manner (a clearly sequenced narrative of events) and with sufficient detail. This difficulty can make them appear to be uncooperative and even non-responsive when they are being questioned by police, attorneys, or judges (see also Kroncke, Willard, \& Huckabee, 2016). Individuals with ASD frequently have difficulty in being able to recollect or remember past personally experienced events and tend to remember fewer of them as well as taking more time to do this when compared to individuals without ASD (Goddard et al., 2007; Crane \& Goddard, 2008; Crane et al., 2012; Crane \& Maras, 2018). These are difficulties that criminal justice professionals need to be aware of and manage appropriately when interviewing an individual with ASD within a forensic setting/context.

The following excerpt from P.J. highlights how stressful this time was for him: "It is difficult for me to remember what I was thinking and how I was feeling at this time; every time I try to remember I feel I start to hyperventilate and feel a wave of grief, as though I am experiencing it all over again. I remember being trapped in a mental loop, thinking about all the little concerns in my life (the support cases that I still needed to work on for my job, game night with my friends, getting the groceries) and how they didn't matter or were about to be destroyed by what had happened".

Following his arrest, the next contact that P.J. had with the police took place after his admission of guilt in court (prior to sentencing) when he became subject to the notification requirements of the Sexual Offences Act 2003 and got involved with the Offender Management Unit (OMU). During this time, P.J. received near weekly visits from a pair of plain clothed officers. The officers were polite and respectful. However, he reports that he: "still felt intimidated by them due to their detailed questioning of where I had been, where I was planning on going and what I did at what time”. Less than a month after his initial sentence was quashed and replaced with a Community Payback Order, P.J. had all his electronic devices seized during a routine home visit. This was an extremely stressful and difficult time for P.J. and his family. There is more detail on this in the section headed 'Experiences following release from prison', subsection 'Seizure of devices a little over a fortnight after my sentence was quashed and replaced with a Community Payback Order' below.

Experiences during the court proceedings

\section{Initial sentencing}

In terms of court proceedings, P.J. reported experiencing feelings of "helplessness". He states that: "In the case of my sentencing, this was far more traumatic, as the person the Sheriff seemed to be describing bore no relation to me or the way I think or the reasons for my behaviour. I was essentially being told they were 
taking my life away for reasons which did not even seem to relate to me and I was not allowed to respond. How could I be a threat to public safety? I had never intentionally harmed anyone or anything in my life and never would. It was always other people who had hurt me. I just didn't understand" (P.J., 2019). No reasonable adjustments or allowances were made for P.J. during the court proceedings. At this time, he had not received his diagnosis of ASD. However, P.J. was experiencing acute anxiety and depression at this time (along with a medical history of anxiety and gastritis spanning more than a decade) and the court had been made aware of this. P.J. also wrote how the Sheriff stated that there were no mitigating factors. P.J. stated that this is not accurate as he had no previous record (it was a first offence), he was employed, had the support of his family and friends and had willingly engaged in support, both through work (Occupation Health assessments) and privately (therapy with a trained Sexologist who has dealt with countless individuals in his position). He also reported that the court had access to his medical records and a report on the matter but it appeared that the court failed to take these into consideration in the sentencing decision.

\section{Appeal Hearing}

When P.J. was in prison his family began preparations for an appeal and contacted the National Diagnosis \& Assessment Service who carried out an assessment with P.J. when he was released on bail after 72 days in prison. He was formally diagnosed with ASD, specifically, High-Functioning Autism (childhood). The decision to go private was made following information that the waiting time within the national health service (NHS) for such assessment can take a minimum of one year. Also, P.J.'s therapist had also informed him that some of her clients were taken off the waiting list when it was found the request for a diagnosis was prompted by a criminal conviction. P.J. states that if his family had not arranged everything while he was still in prison and having the money for a private assessment (which cost over $£ 2,500$ ), it would have been impossible for him to have received a diagnosis prior to his appeal hearing.

However, P.J. reports that there was a lack of certainty whether his diagnosis of ASD would make any difference at his appeal hearing. He states: "My lawyers were so unconvinced that the submission of a diagnostic report would make any difference, that they did not present it to the High Court, until we insisted that they do so on the day of the Hearing. This was due to their own lack of experience with the significance of an autism diagnosis". However, the diagnostic report was pivotal during the appeal. The High Court Judges quashed his sentence and reduced it to a community payback order (with 200 hours unpaid labour) without hearing any testimony from P.J.'s advocate. They acknowledged the Sheriff had been excessive in his sentencing (even without the knowledge of a diagnosis of ASD on which to base his decision). They also specifically cited the significance of the autism diagnosis they had just received from P.J.'s advocate. They ask P.J. if he wished to argue for a further reduction. P.J. accepted the sentence as given as he and his family were grateful that the Judges took the diagnosis of ASD into consideration and understood its importance and impact on his actions. P.J. described how it is "terrifying that another pair [of judges] would possibly not, due 
to lack of individual understanding of the issue" have appreciated the importance of the diagnosis of ASD and how it should be considered in sentencing decisions. Lastly, as highlighted by Steel (2016), a diagnosis of ASD has been used as a defence in a number of IIOC cases. The repetitive behaviours, unusual interests, and inappropriate social interactions which are consistent with ASD have a 'substantial overlap with the behaviours of child pornography offenders' (Steel, 2016).

\section{Experiences in the prison environment}

One of the positive experiences that P.J. had while he was in prison was being able to spend much of his time in isolation. When he first entered the prison, due to the extreme stress he was under, he was placed in a suicide prevention cell for a total of five days (the recommended maximum is 72 hours). After this, he was moved into a protection wing where he was kept in his cell upwards of 23 hours a day with only a 20 minute window (at most) in order to make telephone calls, if the phones were free at the time. He describes being "consciously aware that spending this much time in isolation would possibly be seen as detrimental to my mental wellbeing and physical health." However, he reports that this was nevertheless positive. Specifically, he stated that "Given my acute social anxiety, depression and extreme unfamiliarity with my surroundings and situation, I merely wanted to stick my head under the bed covers and pretend I wasn't there. Being isolated allowed me to all but shut my brain down at times". P.J. had not yet received his formal diagnosis of ASD when he entered prison. However, P.J. reported that "the prison staff appeared to be cognisant of the significance of mental health issues". For instance, he was given a medical interview with an NHS nurse shortly after he arrived, and they reviewed his medical history, taking note of his depression and anxiety. In the final week that P.J. was in the prison, he noticed that there were posters advertising Mental Health Awareness week in all blocks which encouraged prisoners to come forward with any concerns. Despite these positive aspects of the prison, P.J. experienced a number of difficulties and challenges while he was in prison.

\section{Being unprepared for prison}

P.J. describes being "utterly unprepared for going to prison". One of the key reasons for this was that everyone involved (the therapist; lawyer; police officers of the offender management unit) believed that he would receive a community payback order. Therefore, it came as a shock to everyone when he received a custodial sentence. Given this, he was not aware of the various accommodations which can be made in advance of being sent to prison (such as being allowed to pack a bag with a number of approved personal items that can be taken into prison). He also describes being "completely unprepared mentally for the processing". Another issue was the delay in getting his usual medication when he entered prison. It took about a week before he received his medication for depression (Citalopram). This delay occurred even though P.J.'s therapist made contact with the prison directly, stressing the need for them to make this a priority. 
No orientation provided regarding prison life

P.J. described not receiving any orientation on prison life and was not informed of the procedures or his rights to contact his lawyer. However, the prison staff did allow his mother to visit him - despite not having authorisation - four days after he was imprisoned. He was able to provide written instructions to allow her and a number of others to speak on his behalf to his lawyer and employers. The prison environment is a challenge for most people but can be even more so for individuals with ASD (Allely, 2015a, 2015b). Recently, a book was published by Will Attwood called "Asperger's Syndrome and Jail: A Survival Guide". The book provides practical advice covering everything that an individual with ASD needs to know if they are going to prison. Based on his own experience of being in prison, Attwood provides the reader which information on what kind of things to expect and how to behave once you are in prison (Attwood, 2018).

\section{Persistent noise and the impact of other people}

P.J. described noise as being one of the most persistent stressors that he faced: "Among the most persistent was the noise; from about $8 \mathrm{am}$ through to $10 \mathrm{pm}$ there was a near constant stream of noise throughout the facility from other prisoners and staff. While this would have likely been tolerable were it simple background noise, its tendency to suddenly fluctuate for many minutes at a time, combined with the occasional shouting from different halls, or individuals "having a laugh" and banging on my door, created a very tense ambience for me, as someone who has experienced sensory overload in loud locales before. The noise whenever there was a football match was beyond unbearable". In order to endure this (and not being able to get sleep due to excess energy), P.J. stated that he "began dozing off at night much later (as late as 4am) and trying to return to sleep after getting my medication at 8-9am. This allowed me to skip a number of hours of noise, though on a few occasions resulted in missing lunch". This experience is consistent with other reports. For instance, Baron-Cohen (2011) in his book "Zero Degrees of Empathy: A New Theory of Human Cruelty", briefly detailed the case of a man with Asperger's syndrome (AS) who reported having had a terrible experience when he was in prison. His sensory hypersensitivity meant that the noise of the prison was even more deafening to him than it would be to someone without ASD.

Most people would probably find the prison environment to be really noisy and some may find this too much. However, for many individuals with ASD, the noise can be overwhelming and distressing. It is the level of intensity of the distress to the noise which typically distinguishes the individual with ASD from those without ASD. This is a very important distinction to consider. Sensory hyper-and hypo-sensitivities are a common feature in individuals with ASD. Sensory sensitivities are included as a criterion for the classification of ASD in the DSM-5 (APA 2013). Studies have identified that one of the most commonly reported sensory sensitivities in individuals with ASD is a sensitivity to sounds (e.g., Kern et al., 2006; Jones et al., 2009; 
Haesen et al., 2011). It has also been found that particular sounds are perceived as being more intense by individuals with ASD. For instance, certain frequencies can be perceived as being extremely annoying (e.g., computer fan; sounds from overhead lights) and loud noises can be experienced as being painful (e.g., car horn; ambulance siren). Additionally, sounds which are combined (e.g., a number of people talking to each other at the same time) can be overwhelming (see Elwin et al., 2012; Robertson et al., 2015). Another important issue is that it has been suggested that some individuals with ASD are unable to get used to certain types of sensory stimuli in the way that individuals without ASD appear to do - something which is known as habituation (Robertson et al., 2015). It may be that over time, individuals without ASD may be able to habituate to the noise of the prison environment whereas some individuals with ASD may not be able to do this, making the noise of the prison environment overwhelming.

P.J. also describes that when he was in prison, what may have been one of the most pervasive sources of stress was other people. P.J. has a long history of experiencing social anxiety when in crowds and groups of people. This had previously led him to ask to be transferred to his work's night shift team in order to avoid the stress of having other people around him. He describes the following regarding the experience of having other people around him in the prison environment: "Knowing that I was constantly surrounded by people whether they were on the other side of a locked steel door or not - with no way of isolating myself further was extremely distressing, and lead to me trying to 'shut down'...more and more". These experiences by P.J. are consistent with many individuals with ASD. Social anxiety disorder and stress about being in crowds, etc. is a commonly reported comorbidity in individuals with ASD (e.g., Gillott \& Standen, 2007; Maddox \& White, 2015).

\section{Physical difficulties due to being on the protection wing}

In an earlier section, P.J. reports the positive aspects of spending much of his time in isolation in the prison (23 hours a day). While this has a positive benefit to him psychologically, there were physical disadvantages to this. He describes how his "back and sides quickly became sore from the plastic furnishings". In order to alleviate this, he would adopt strategies. He describes these in the following excerpt: "I found myself lifting bottles I had filled with water and walking in circles around the small cell for hours at a time, trying to burn off enough energy to fall asleep (figure of 8, diagonally from the table to the door, 7 steps each way - I remember feeling like a gerbil kept in a small cage)".

Complete lack of knowledge of the culture of a prison and the large amount of "unwritten rules" and jargon amongst both the prisoners and guards

Another source of stress was the "complete lack of knowledge of the culture of a prison; besides the fact I never had ANY orientation the entire time I was there (leading to a lot of difficulties learning how to 
order meals, update my visitor list, add phone contacts or have laundry collected), there were a large amount of "unwritten rules" and jargon amongst both the prisoners (whom I met while collecting meals) and guards, that I did not understand. Learning these was a stressful and, at times, embarrassing process". In a previous study by Morris (2009), one of the participants (an individual with ASD), reported the challenges that he faced when speaking with other inmates. In another study, one of the two participants with ASD reported feeling isolated from the majority of the prison population as a result of his inability to interact appropriately with other inmates (Paterson, 2008).

\section{Uncertain schedule within the prison}

It is well established that individuals with ASD like to adhere to a routine and any deviation or disruption to this routine can result in distress. It is a common belief that the structure and routine within a prison would be the ideal situation for individuals with ASD. However, this is often not the case. A number of things can occur within the prison environment which results in a disruption to routine (such as lock-down, lack of staff, etc). P.J. also mentioned the uncertain schedule for 'recreation' within the prison was a frequent source of stress for him. He says that: “...I was kept in my cell upwards of 23 hours a day, as I was in a 'protection' block, however this hall also had a population of non-protected prisoners, who were allowed to wander during the day. Once this non-protected population were returned to their cells (around 7pm typically) we were allowed out to wander the hall ourselves for up to 20 minutes, however this could be much less depending on the scheduling for the day. This was the only time we were allowed to wander the hall, collect supplies such as toiletries, dispose of rubbish, collect forms for requests (such as medical referrals or changes to visitor lists) and use the phones. In some cases, I was unable to call home to speak to my family due to the variable length of this window, which heightened both my stress and that of my family". Indeed, this is a source of stress reported by individuals in previous studies which have explored the experiences of individuals with ASD within the prison environment (although as pointed out by Allely, 2015a, 2015b) there are relatively little studies which have been carried out to date exploring the experiences of individuals with ASD within secure environments such as prison. In the study carried out by Morris (2009) one of the participants with ASD within the prison reported that the consistency of routine was a positive aspect but that if there was any delay in the routine activities he could become anxious and angry.

\section{Lack of regular and timely updates provided regarding legal affairs and messages from family}

An additional element of stress in the later weeks of P.J.'s imprisonment was the lack of updates which he was provided regarding his legal affairs (there were no channels of communication to rapidly update him about requests from his lawyer, to find out the results of his sift or to obtain updates on his bail hearing (e.g., P.J. gives the example of how his mother would send emails but these would take two to three days to be delivered to him). [For details on Sift in Scots Law, see section 31.2 in 
https://www2.gov.scot/Publications/2004/03/19042/34208. The Sift Judge considered (at the first Sift) that P.J.'s appeal had a good chance of success and it was allowed to go ahead. P.J.'s lawyers requested bail (interim liberation) until his appeal hearing was heard. It was a further two weeks before this was granted and he was released. He was told it could take 4-5 months before his Hearing was heard but it only took 19 days. If the Appeal Court Judges had only reduced his sentence and not quashed it he would have had to return to prison. This caused extreme stress for the 19 days after he was released from prison as the thought of having to return was too much for him or his family to bear.]. This (in addition to scheduling issues) P.J. states "lead to considerable stress on days that I thought would lead to tangible progress in my case. On the day I was released, the first thing I knew about it was when a guard came to collect me at 3pm, despite my family having known for several hours".

\section{Difficulties in getting correct information}

Another negative aspect of prison was the difficulty in getting the correct information and getting through to relevant people. P.J. states: "My family also had difficulty, as they attempted to reach out to the family liaison service without any success for over a week. Even after eventually establishing contact, they were given wrong information about what was permissible and what the procedure for sending in personal effects actually was. That was the one and only time they managed to get through to them! They got more helpful information from talking to relatives of other inmates whilst sitting in the waiting room".

\section{Experiences following release from prison}

Since being released from prison, P.J. has experienced numerous difficulties and challenges. These are outlined below.

Seizure of devices a little over a fortnight after his sentence was quashed and replaced with a Community Payback Order

The most difficult thing that P.J. had to deal with since his release from prison was the seizure of his devices about two weeks after his sentence was quashed and replaced with a Community Payback Order. Following his first appointment with the social workers, P.J. received a standard visit from the police of the Offender Management Unit (OMU). During this first appointment they reviewed P.J.'s phone and desktop computer browsing history. P.J. had made sure to keep his browsing history and left any files downloaded from the internet in his Downloads Folder for them to find easily. However, he points out that he did this only "to keep myself right". There were no requirements from the High Court judges to do this (there were no specific restrictions on his internet use). The police had previously advised P.J. that he could still view 
pornography but to keep himself safe. Additionally, his therapist suggested it could help his depression but suggested he reduce the time he engaged in this activity slowly.

However, when the police saw the downloads and the pornography they were immediately concerned about what they saw as an excessive amount of material stored in his history (again this issue of the amount of images or downloads being considered indicative of risk rather than associated with the ritualistic/collecting aspect of ASD) and then began questioning the age of individuals in the few files that he had downloaded (although P.J. downloaded the videos in question from what he had assumed to be legal sites). As a result, the police detained P.J., obtained a warrant to seize all of his electronic devices and held him at a police station for half a day until they were able to arrange an interview. P.J. was informed by the police at this point that the sites he had visited were 'suspicious' and that it was likely he was going to be charged again. This obviously caused P.J. high levels of stress and anxiety as “...at any moment I could be arrested again and charged". He states that: "This event caused my family to lose a considerable amount of trust in me, and the resulting confrontations we had due to our heighted stress levels caused me to suffer from even greater anxiety and depression than ever before". An initial search of his devices revealed nothing illegal, so they were sent away for review by the cybercrimes division. P.J. was released that evening without charge (after answering 'no comment' during a police interview with his lawyer and an assigned appropriate adult present). The forensic report, following review of the seized devices by the cybercrimes divisions, was completed over a year later. Having waited over a year, the results of the cybercrimes forensic report revealed that there was no illegal content on any of the devices and they would not be charging P.J.

Over time P.J. has suggested that this misunderstanding stemmed from his ASD. He states that: "It was my understanding that the word 'teen' would refer to individuals of $18+$ years of age if you were viewing legitimate, legal websites. Further cementing this in my mind were the disclaimers on such sites which to me was seen as a guarantee - I even said as much to the police while they were preparing to detain me, at which point one of them asked, "what do you think a disclaimer means, legally?" I replied that it meant everything was legal. It was not until I gave an account to my mother of the questions the police had asked and how I had responded that I discovered what a disclaimer really meant! This sudden realisation that I had misunderstood what seemed obvious to everyone else, along with the fact that individuals with autism are known to have issues with determining the ages of individuals from sight alone (I have had trouble telling the ages of older individuals all my life) as the variability of human appearance means it is not an exact (ie. Systemised) science, lead to the further fear that I had indeed reoffended, albeit unwittingly." Again, we can see here how ASD can put an individual at risk of viewing material online which is illegal. Things that are obvious to individuals without ASD are not so obvious to individuals with ASD. Additionally, with regard to reading ability, an individual with ASD may initially appear to be able to read well. However, some individuals with ASD can superficially read text without fully understanding what it means (this is referred to as 'hyperlexia'). 
This may be another explanation for P.J.'s lack of understanding of the meaning of the word disclaimer (The Advocate's Gateway, 2016).

P.J. goes on to describe how this also resulted in a tightening of his order's restrictions at the behest of the social work team. The reason for this was that they were worried that he could not accurately determine ages given how long he had previously been offending. This led to them applying to the High Court for an Order to restrict his use of the internet. P.J. (because he was not eligible for legal aid) had to pay over a thousand pounds for his lawyers to go back to court to accept these restrictions on his behalf. The new rules stated that P.J. could not use any internet or file storage enabled device that the police and social work had not jointly approved. After more than a year, the only device that P.J. is approved to use is his phone. It is useful at this point to highlight that P.J. was not doing anything illegal here. Here, the symptomology of ASD made the social work team consider him to be more at risk requiring further restrictions and the police did not consider issues such as how the amount of pornographic material that P.J. had was unrelated to level of risk or breaking of orders and more related to the ritualistic nature of ASD.

Negative impact of device restrictions placed on P.J. as a direct result of this police investigation

As a direct result of the police investigation (which revealed nothing after over a year) device restrictions were placed on P.J. These device restrictions have had a significant negative impact on P.J. For instance, it has caused issues with his attempt to return to University to study for a Masters degree. As he is on the Sex Offenders Register (SOR) he is not in a strong position to return to work. Moreover, the Department for Work and Pensions (DWP) have classified P.J. as unfit for work, after sending him to a mental health assessment which is why P.J. has sought to return to University instead. He has also "lost the ability to unwind by playing computer games, or even use a computer for any work, entertainment or research related purposes". Prior to the restrictions, P.J. used to play computer games during his free time as he "enjoyed the level of escapism they granted". He is now prohibited from playing any gaming device (such as his Nintendo 64, N64, which is a cartridge-based games console released in 1996) due to the fact that the device has the capacity to connect to the internet. He goes on to describe that he has "lost a prominent hobby that used to help me deal with stress and I raised the issue that such resulting boredom can be detrimental to a person's mental health". As mentioned in the previous section, the only device that has ever been approved is P.J.'s phone. He also states that "This has caused me immense frustration, as technology has been my life - it has consumed my academic work and social life going back a long time and playing computer games is my prime source of relaxation".

\section{Challenges with attempting to adhere to restrictions}


As mentioned above, P.J. has a number of restrictions (e.g., only use an approved device; always keep a browser history; do not install bleaching software; do not have unsupervised contact with individuals under 16/17 (this figure tends to vary depending on who you ask); do not use social media; do not go to parks where children congregate and do not take work in a place children may be present). While many of these appear clear in written form, some of them strain logic when put into practice, or are utterly unwritten. P.J. describes an example of this when he went to the cinema with his father to see a 12A rated film one afternoon. It was a $12 \mathrm{~A}$ meaning anyone under that age would be supervised, he did not communicate with anyone in the cinema and his father was with him the entire time (hence would - by the wording on the order - not be having unsupervised contact). When he reported that he had been to see the film at the next appointment he had with social work, the social worker was critical of this and reported it to his superior as a possible breach. P.J. states that: "the fact that I had gone to the cinema without letting social work or the OMU know in advance (a requirement that is not listed in ANY of the documentation) and that it was around 4pm when there was a possibility of children being present, was almost enough for me to receive a breach in my order, which could have had very serious consequences". Another important issue that is raised by P.J. is regarding the adherence to the specific requirements of the order (restriction orders) which he considers to be "open to interpretation". He gives the example of the requirement stating that he needs to stay away from parks where children congregate. He points out that this could be read that it is okay to go to parks where there are not children congregating. Issues such as this would be even more difficult for individuals with ASD. It is well-established in the literature that individuals with ASD have difficulty transferring knowledge from one situation to another, for instance.

\section{Difficulties with early sessions with social workers}

P.J. reports having experienced a difficult time initially with the social workers. His initial sessions with the CJSW team involved much emotion and tears as he tried to explain his past and the history of his offending. He states that: "This was made very difficult by the senior social worker who repeatedly would change the subject (the phrase, "lets put a pin in that" was very common) and then criticise me in later sessions when I did not provide what she saw as vital context at the time. I tried to explain that I was trying to give them my history in a structured fashion from start to finish, so that all the chronological context would make sense, however her tendency to jump around to points she found interesting was disrupting this greatly. In response, she said that I had to learn to provide them with information the way they were used to, not taking heed of my claims that I was having difficulty with such a random, asynchronous summary of several decades of development". Again, as mentioned earlier in relation to the police interview, evidence suggests that individuals with ASD are often impaired in their ability to recall events in a sequential manner (a clearly sequenced narrative of events) and with sufficient detail. This difficulty can make them appear to be uncooperative and even non-responsive when they are being questioned (see also Kroncke, Willard, \& Huckabee, 2016). P.J. found that the earlier sessions with the social workers "lead to great amounts of 
frustration and difficulty communicating with the team, especially when different members were occasionally present at different times". The statement that the social worker makes that P.J. "had to learn to provide them with information the way they were used to, not taking heed of my claims that I was having difficulty with such a random, asynchronous summary of several decades of development". It took many weeks of appointments before things stabilised. Eventually, P.J. was able to give the full details of his offending history (albeit out of sequence) and was scheduled with the same social worker consistently. From then on, P.J. states that things became more routine. Rather than provide a course of action or points to reflect upon to ensure that he does not reoffend, his appointments consisted of meeting his social worker at the council offices to discuss what he had been doing since the last time they met, etc.

\section{External support and support of family and/or friends following release from prison}

P.J.'s family (in particular his mother) have continued to support him throughout the entirety of his legal ordeals (e.g., trying to help him regain his job, seek new employment, engage in services that are beneficial and helping him return to University). Another source of support for him has been his long-time friend, G.S. whom he first met in High School. Following his release from prison, P.J. did receive external support from others besides his family members and friends. Specifically, he renewed contact with his therapist. He describes that "she regrettably had to dial back and eventually call a halt to our talks due to medical problems (she spent several months recovering from the removal of a cancerous growth), she provided me with help in dealing with the stress I experienced during my time in prison and discussed my autism in detail, in the context of much of what we had discussed in the previous year". P.J. also said that the National Diagnosis \& Assessment Service (NDAS) provided what he felt was the most support for him in the month immediately following his release, leading up to his appeal.

Measures and support that could have been useful

P.J. had a family who provided support for him throughout his whole involvement with the criminal justice system - as well as supporting him in undergoing assessment where he was diagnosed with ASD. What was also key in this case study is that P.J. had High Court Judges who, during his appeal hearing, were able to recognise the importance of his diagnosis on his offending behaviour and provide an alternative to a sentence. P.J. suggests a number of measures which would have helped him at various stages of his involvement with the criminal justice system. These are detailed below.

- Need for early identification of ASD and provision of information regarding ASD and different types of offending behaviour (e.g., leaflets with links to charities such as Stop It Now!). P.J. notes that he 
only received information such as leaflets from Stop It Now! when he was released on bail. Having had this much earlier would have been useful.

- Presentencing mental health assessment, opt-in or otherwise. P.J. reported that this would have been useful for him. He had concerns about his mental health prior to his conviction but did not feel able to pursue it further due to the rigid scheduling involved in the courts. There is also the need for an improved referral system for adults with suspected ASD (or other mental health concerns) on the NHS.

- P.J. also stated that it would also have been helpful if the National Autistic Society (NAS) could have offered some support and liaised with human resources (HR) in his work to talk about how the diagnosis of ASD contributed to P.J.'s offending behaviour. P.J. was dismissed from his employment, with the reason being gross misconduct for not following absence procedures, noting that the absence guidelines require the individual in question to make contact, not a proxy as in P.J.'s case and reputational damage to the company. P.J. points out that the HR lead did not seem to understand the relevance of the autism report, or that P.J. had done everything he could to follow company policy, given the circumstances. P.J. and his family wanted to take them to an employment tribunal but decided against this because P.J.'s name would be made public and details of the case would be given on the Employment Tribunal website.

- There is a need for greater training for court officials and other criminal justice professionals (including social workers who carry out CJSW assessments) on ASD. Specifically, training focused not just on the symptomology but how this symptomology can contribute to different types of offending behaviours. As pointed out by P.J., in his own experience, the high court appeal judges both understood the implications of his diagnosis of ASD and its significance in the context of offending. However, this was not the case for the other sheriffs, lawyers and prosecutors that he encountered up until that point. The Sheriff during P.J.'s sentencing used his discretion to pass a more severe sentence (see also Allely \& Cooper, 2017).

- P.J. has suggested that amending the restrictions would be useful. For instance, giving examples would be beneficial. Also, having an "appropriate adult" who is trained in assisting individuals with learning difficulties or neurodevelopmental disorders (for instance) and insuring they understand each point would be also be useful.

\section{Limitations and strengths}


One of the main limitations with this paper is that it is based on a single case study. However, this is the first case study to be published in an academic journal, to the authors knowledge, which explores the contributory role of ASD symptomology to the viewing of IIOC and the experience of the criminal justice system. There was also no available information regarding the police, prison staff or social workers involved in the case. The case study only provides the view of the defendant which is a limitation. However, knowledge in this field is in its infancy so to highlight the importance of this area though case study is crucial at this juncture. It is hoped that it will drive the need for more understanding and the development of larger scale empirical studies.

\section{Clinical and Legal Implications and Recommendations}

In the literature, there is an increasing interest in the 'draconian sentences' that individuals with ASD face after being found guilty of violating child pornography (IIOC) statutes (Mahoney, 2009, pp. 48-52). Usually, sentences will involve mandatory extended prison terms and mandatory minimum sentences that defendants need to serve before they can be considered eligible for parole. Unlike in ordinary cases (where the defendant is neurotypical) when the defendant has neurological deficits (e.g., ASD) the sentences not only can be considered unduly harsh but potentially serve no 'reasonable protective purpose' (e.g., protecting children). In prison, individuals with ASD will be unable to download IIOC (Douard \& Schultz, 2017). Mesibov and Sreckovic (2017) have also stated that, with individuals with ASD who have downloaded IIOC, prison sentences are not absolutely necessary because of the extremely low risk which individuals with ASD present of harming a child (Mesibov \& Sreckovic, 2017). Instead, support, intervention and/or psychoeducation is needed. As pointed out by Mahoney (2009) the following factors contribute to an individual with ASD engaging in the viewing of IIOC.

- Unbridled curiosity of ASD individuals

- ASD individuals' interest is not necessarily deviant - "counterfeit deviance"

- IIOC's mere existence on the internet sends the message of legality to the ASD teen or young adult

- ASD individuals' inability to intuit social mores and legal rules

- Empathic deficits (but note that individuals with ASD do have empathy when told that the children in the images are victims and are in distress, etc)

- Unless explicitly explained, ASD individuals fail to see the harm in merely viewing or receiving IIOC

- Distinction between of-age and underage females is intentionally blurred by the media and pop culture and legal "adult" porn (Mahoney, 2009)

\section{Conclusion}


There is a very real and urgent need for the innate vulnerabilities which are associated with ASD which can contribute to offending behaviour such as the viewing of IIOC, to be recognised in criminal law (Allely \& Dubin, 2018; Allely et al., 2019; Freckelton \& List, 2009; Freckelton, 2011, 2013). Currently, the understanding of the association between ASD and engaging in viewing of IIOC is poorly recognised and understood both by the general public as well as clinical and legal professionals. The importance of addressing this has been recently raised (Dubin \& Horowitz, 2017; Allely \& Dubin, 2018; Allely, Kennedy, \& Warren, 2019). The case presented here stresses the importance of early recognition and diagnosis of ASD in order to receive a fair trial (see also Cooper \& Allely, 2017). The information that P.J. provided the author in his responses to each of the questions in the questionnaire (much of which was not included in this paper due to a number of reasons including journal word restrictions and the need to avoid the inclusion of any information which may result in the identification of P.J.) provide the reader with a deeply personal and insightful account of his experiences. It must also be noted that P.J. does not benefit directly from having taken part in this. However, he and his family recognise that there are many other individuals with ASD that will go through, or are going through, what he did. P.J.'s experience caused a substantial amount of stress and anxiety on both himself and his family who supported him throughout (and continues to significantly impact on his life). Like the author, P.J. hopes that his personal account will help others who find themselves in a similar position. It is hoped that this case study will provide insight and understanding into the association and raise awareness of the need to consider this at all stages of the criminal justice system, including in sentencing decisions. It will also more effectively inform the development of appropriate preventative strategies and timely interventions.

\section{Acknowledgements}

The author would like to thank P.J. for his time and dedication to completing the questionnaire upon which this paper was based.

\section{Conflicts of Interest}

The author has no conflicts of interest to declare

\section{Funding}

This case study project was unfunded.

\section{References}


Allely, C. S., Kennedy, S., \& Warren, I. (2019). A legal analysis of Australian criminal cases involving defendants with autism spectrum disorder charged with online sexual offending. International Journal of Law and Psychiatry, 66, 101456.

Allely, C. S. (2019). Firesetting and arson in individuals with autism spectrum disorder: a systematic PRISMA review. Journal of Intellectual Disabilities and Offending Behaviour.

Allely, C. S., \& Dubin, L. (2018). The contributory role of autism symptomology in child pornography offending: why there is an urgent need for empirical research in this area. Journal of Intellectual Disabilities and Offending Behaviour, 9(4), 129-152.

Allely, C. S., \& Faccini, L. (2018). Rare instances of individuals with autism supporting or engaging in terrorism: a reply. Journal of Intellectual Disabilities and Offending Behaviour, 9(1), 64-66.

Allely, C. S., \& Cooper, P. (2017). Jurors' and judges' evaluation of defendants with autism and the impact on sentencing: a systematic Preferred Reporting Items for Systematic Reviews and Meta-analyses (PRISMA) review of autism spectrum disorder in the courtroom. Journal of Law and Medicine, 25(1).

Allely, C., \& Creaby-Attwood, A. (2016). Sexual offending and autism spectrum disorders. Journal of Intellectual Disabilities and Offending Behaviour, 7(1), 35-51.

Allely, C. S. (2015a). Experiences of prison inmates with Autism Spectrum Disorders and the knowledge and understanding of the spectrum amongst prison staff: A review. Journal of Intellectual Disabilities and Offending Behavior, 6(2), 55 - 67.

Allely, C. S. (2015b). Autism spectrum disorders in the criminal justice system: police interviewing, the courtroom and the prison environment. Recent Advances in Autism, 1-13.

American Psychiatric Association. (2013). Diagnostic and statistical manual of mental disorders (5th ed.). Washington, DC: Author.

Attwood, T., Hénault, I., \& Dubin, N. (2014). The Autism Spectrum, Sexuality and the Law: What every parent and professional needs to know. London, UK: Jessica Kingsley Publishers.

Baron- Cohen, S. (1988). An assessment of violence in a young man with Asperger's syndrome. Journal of Child Psychology and Psychiatry, 29(3), 351-360. 
Baron-Cohen, S., Leslie, A. M., \& Frith, U. (1985). Does the autistic child have a "theory of mind"?. Cognition, 21(1), 37-46.

Barry-Walsh, J. B., \& Mullen, P. E. (2004). Forensic aspects of Asperger's Syndrome. Journal of Forensic Psychiatry and Psychology, 15(1), 96-107.

Brugha, T. S., McManus, S., Bankart, J., Scott, F., Purdon, S., Smith, J., ... \& Meltzer, H. (2011). Epidemiology of autism spectrum disorders in adults in the community in England. Archives of General Psychiatry, 68(5), 459-465.

Chesterman, P., \& Rutter, S. C. (1993). Case report: Asperger's Syndrome and sexual offending. The Journal of Forensic Psychiatry, 4(3), 555-562.

Crane, L., \& Maras, K. (2018). General Memory Abilities for Autobiographical Events in Adults with Autism Spectrum Disorder. The Wiley Handbook of Memory, Autism Spectrum Disorder, and the Law, 146-178.

Crane, L., Pring, L., Jukes, K., \& Goddard, L. (2012). Patterns of autobiographical memory in adults with autism spectrum disorder. Journal of Autism and Developmental Disorders, 42(10), 2100-2112.

Crane, L., \& Goddard, L. (2008). Episodic and semantic autobiographical memory in adults with autism spectrum disorders. Journal of Autism and Developmental Disorders, 38(3), 498-506.

Creaby-Attwood, A., \& Allely, C. S. (2017). A psycho-legal perspective on sexual offending in individuals with Autism Spectrum Disorder. International Journal of Law and Psychiatry, 55, 72-80.

Cooper, P., \& Allely, C. S. (2017). You can’t judge a book by its cover: evolving professional responsibilities, liabilities and 'judgecraft' when a party has Asperger's Syndrome. Northern Ireland Legal Quarterly, 68(1), $35-58$.

Cutler, E. (2013), “Autism and child pornography: a toxic combination", available at: http://sexoffenderstatistics. blogspot.com/2013/08/autism-and-child-pornography-toxic.html

Debbaudt, D. (2004), "Beyond guilt or innocence”, forum paper, Autism New Zealand Inc., Worcester, MA, available at: http://autismnz.org.nz/police/Pol_BeyGuilt.pdf

Douard, J., \& Schultz, P. (2017). Chapter 12. Asperger's syndrome and downloading child pornography: Why criminal punishment is unjust and ineffective. In Caught in the Web of the Criminal Justice System: Autism, 
Developmental Disabilities, and Sex Offenses. Edited by Lawrence A. Dubin, J.D. and Emily Horowitz, Ph.D. Foreword by Alan Gershel, J.D. Introduction by Mark Mahoney, J.D. Afterword by Tony Attwood. Jessica Kingsley Publishers.

Dubin, L.A., \& Horowitz, E. (2017). Caught in the web of the criminal justice system: Autism, developmental disabilities, and sex offenses. London, UK: Jessica Kingsley Publishers.

Elwin, M., Ek, L., Schröder, A., \& Kjellin, L. (2012). Autobiographical accounts of sensing in asperger syndrome and high-functioning autism. Archives of Psychiatric Nursing, 26(5), 420-429.

Everall, I. P., \& Lecouteur, A. (1990). Firesetting in an adolescent boy with Asperger's syndrome. The British Journal of Psychiatry, 157(2), 284-287.

Fernell, E., Eriksson, M. A., \& Gillberg, C. (2012). Early diagnosis of autism and impact on prognosis: a narrative review. Clinical Epidemiology 5, 33-43.

Fombonne, E. (2009). Epidemiology of pervasive developmental disorders. Pediatric Research, 65(6), 591598.

Freckelton, I. (2011). Autism spectrum disorders and the criminal law. In Mohammadi, M.-R. (Ed.), A comprehensive book on autism spectrum disorders (pp. 249-272). [IntechOpen]. doi: 10.5772/975

Freckelton, I. (2013). Forensic issues in autism spectrum disorder: Learning from court decisions. [IntechOpen]. doi: 10.5772/55400

Freckelton Sc, I., \& List, D. (2009). Asperger's disorder, criminal responsibility and criminal culpability. Psychiatry, Psychology and Law, 16(1), 16-40.

Gillott, A., \& Standen, P. J. (2007). Levels of anxiety and sources of stress in adults with autism. Journal of Intellectual Disabilities, 11(4), 359-370.

Goddard, L., Howlin, P., Dritschel, B., \& Patel, T. (2007). Autobiographical memory and social problem solving in Asperger's syndrome. Journal of Autism and Developmental Disorders, 37(2), 291-300.

Griffin-Shelley, E. (2010). An Asperger's adolescent sex addict, sex offender: A case study. Sexual Addiction and Compulsivity, 17(1), 46-64. 
Haesen, B., Boets, B., \& Wagemans, J. (2011). A review of behavioural and electrophysiological studies on auditory processing and speech perception in autism spectrum disorders. Research in Autism Spectrum Disorders, 5(2), 701-714.

Haskins, B. G., \& Silva, J. A. (2006). Asperger's disorder and criminal behavior: Forensic-psychiatric considerations. The Journal of the American Academy of Psychiatry, 34(3), 374-384.

Hingsburger, D., Griffiths, D., \& Quinsey, V. (1991). Detecting counterfeit deviance: Differentiating sexual deviance from sexual inappropriateness. The Habilitative Mental Healthcare Newsletter, 10(9), 51-54.

Kana, R. K., Maximo, J. O., Williams, D. L., Keller, T. A., Schipul, S. E., Cherkassky, V. L., ... Just, M. A. (2015). Aberrant functioning of the theory-of-mind network in children and adolescents with autism. Molecular Autism, 6(1), 59-70.

Kern, J. K., Trivedi, M. H., Garver, C. R., Grannemann, B. D., Andrews, A. A., Savla, J. S., \& Schroeder, J. L. (2006). The pattern of sensory processing abnormalities in autism. Autism: The International Journal of Research and Practice, 10(5), 480-494.

Jones, C. R., Happe, F., Baird, G., Simonoff, E., Marsden, A. J., Tregay, J., \& Charman, T. (2009). Auditory discrimination and auditory sensory behaviours in autism spectrum disorders. Neuropsychologia, 47(13), $2850-2858$.

Kroncke, A. P., Willard, M., \& Huckabee, H. (2016). Forensic assessment for autism spectrum disorder. In Assessment of autism spectrum disorder (pp. 345-373). Springer, Cham.

Lazaratou, H., Giannopoulou, I., Anomitri, C., \& Douzenis, A. (2016). Case report: Matricide by a 17-year old boy with Asperger's syndrome. Aggression and Violent Behavior, 31, 61-65.

Ledingham, R., \& Mills, R. (2015). A preliminary study of autism and cybercrime in the context of international law enforcement. Advances in Autism, 1(1), 2-11.

Liebling, A., Hulley, S., \& Crewe, B. (2011). Conceptualising and measuring the quality of prison life. The SAGE handbook of criminological research methods, 358-372.

Maddox, B. B., \& White, S. W. (2015). Comorbid social anxiety disorder in adults with autism spectrum disorder. Journal of Autism and Developmental Disorders, 45(12), 3949-3960. 
Mahoney, M. (2009). Asperger's Syndrome and the criminal Law: The special case of child pornography.

Retrieved from

http://www.harringtonmahoney.com/content/Publications/AspergersSyndromeandtheCriminalLawv26.pdf

McPartland, J. C., Law, K., \& Dawson, G. (2016). Autism spectrum disorder. Encyclopedia of Mental Health, 124-130.

Melvin, C. L., Langdon, P. E., \& Murphy, G. H. (2017). Treatment effectiveness for offenders with autism spectrum conditions: a systematic review. Psychology, Crime and Law, 23(8), 748-776.

Mesibov, G., \& Sreckovic, M. (2017). Child and juvenile pornography and autism spectrum disorder. In A. Lawrence, J.D. Dubin, \& E. Horowitz (Eds.), Caught in the web of the criminal justice system: Autism, developmental disabilities, and sex offenses (pp. 64-93). London, UK: Jessica Kingsley Publishers.

Morris, A. (2009), “Offenders with Asperger's syndrome: experiences from within prison”, doctoral dissertation, Pacific University, available at: http://commons.pacificu.edu/spp/525 Accessed on 21/08/2019.

Mouridsen, S. E., Rich, B., Isager, T., \& Nedergaard, N. J. (2008). Pervasive developmental disorders and criminal behaviour: A case control study. International Journal of Offender Therapy and Comparative Criminology, 52(2), 196-205.

Murrie, D. C., Warren, J. I., Kristiansson, M., \& Dietz, P. E. (2002). Asperger's syndrome in forensic settings. International Journal of Forensic Mental Health, 1(1), 59-70.

Osborn, J., Elliott, I., Middleton, D., \& Beech, A. (2010). The use of actuarial risk assessment measures with UK internet child pornography offenders. Journal of Aggression, Conflict and Peace Research, 2(3), 16-24.

Paterson, P. (2008). How well do young offenders with Asperger syndrome cope in custody? Two prison case studies. British Journal of Learning Disabilities, 36(1), 54-58.

Robertson, A. E., \& David, R., \& Simmons, R. (2015). The sensory experiences of adults with autism spectrum disorder: A qualitative analysis. Perception, 44(5), 569-586.

Schwartz-Watts, D. M. (2005). Asperger's disorder and murder. Journal of the American Academy of Psychiatry and the Law Online, 33(3), 390-393. 
Simonoff, E., Pickles, A., Charman, T., Chandler, S., Loucas, T., \& Baird, G. (2008). Psychiatric disorders in children with autism spectrum disorders: prevalence, comorbidity, and associated factors in a populationderived sample. Journal of the American Academy of Child and Adolescent Psychiatry, 47(8), 921-929.

Siponmaa L, Kristiansson M, Jonsson C, et al (2001) Juvenile and young adult mentally disordered offenders: the role of child neuropsychiatric disorders. Journal of American Academy of Psychiatry and the Law; 29, $420-6$.

Stabenow, T. K. (2011). A method for careful study: A proposal for reforming the child pornography guidelines. Federal Sentencing Reporter, 24(2), 108-136.

Steel, C. (2016). The Asperger's defence in digital child pornography investigations. Psychiatry, Psychology and Law, 23(3), 473-482.

Sugrue, D. P. (2017). Chapter 4. Forensic assessment of individuals with autism spectrum charged with child pornography violations. In Caught in the Web of the Criminal Justice System: Autism, Developmental Disabilities, and Sex Offenses. Edited by Lawrence A. Dubin, J.D. and Emily Horowitz, Ph.D. Foreword by Alan Gershel, J.D. Introduction by Mark Mahoney, J.D. Afterword by Tony Attwood. Jessica Kingsley Publishers.

The Advocate's Gateway (2016). Planning to question someone with an autism spectrum disorder including Asperger syndrome. Toolkit 3 (1 December 2016). Available: https://www.theadvocatesgateway.org/images/toolkits/3-planning-to-question-someone-with-an-autismspectrum-disorder-including-asperger-syndrome-2016.pdf Accessed on $2^{\text {nd }}$ September 2019.

Uljarevic, M., \& Hamilton, A. (2013). Recognition of emotions in autism: a formal meta-analysis. Journal of Autism and Developmental Disorders, 43(7), 1517-1526.

Woodbury-Smith, M. R., Clare, I. C., Holland, A. J., Kearns, A., Staufenberg, E., \& Watson, P. (2005). A case-control study of offenders with high functioning autistic spectrum disorders. Journal of Forensic Psychiatry and Psychology, 16(4), 747-763. 